Discussion Paper No. 13-020

\title{
Investment under Uncertainty and Regulation of New Access Networks
}

Roman Inderst and Martin Peitz

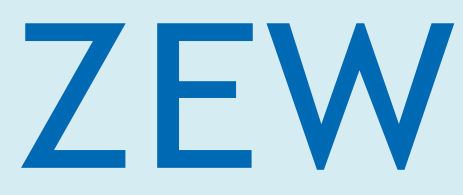

Zentrum für Europäische Wirtschaftsforschung $\mathrm{GmbH}$ Centre for European Economic Research 
Discussion Paper No. 13-020

\title{
Investment under Uncertainty and Regulation of New Access Networks
}

\author{
Roman Inderst and Martin Peitz
}

Download this ZEW Discussion Paper from our ftp server:

http://ftp.zew.de/pub/zew-docs/dp/dp13020.pdf

Die Discussion Papers dienen einer möglichst schnellen Verbreitung von neueren Forschungsarbeiten des ZEW. Die Beiträge liegen in alleiniger Verantwortung der Autoren und stellen nicht notwendigerweise die Meinung des ZEW dar.

Discussion Papers are intended to make results of ZEW research promptly available to other economists in order to encourage discussion and suggestions for revisions. The authors are solely responsible for the contents which do not necessarily represent the opinion of the ZEW. 


\section{Non-technical Summary}

Contractual and regulatory provisions for access affect incentives to invest in an upgraded network and, in particular, a next-generation access network. Investment decisions are made under uncertainty and have to be made over time. This papers provides a framework for taking uncertainty, risk aversion, and the timing of investment explicitly into account. First, it evaluates various access price policies in a framework in which the incremental value over the legacy network is uncertain. Second, introducing risk aversion, the access price structure turns out to be critical for the risk profile of the investing telecom operator and of the access-seeking alternative operator. Third, some implications of the time structure of access payments are derived.

Keywords: NGA, investment under uncertainty, access price rule, telecommunications 


\section{Das Wichtigste in Kürze}

Vertragliche und regulatorische Zugangsbestimmungen beeinflussen die Anreize eines Netzbetreibers, in ein leistungsfähigeres Netz zu investieren. Dies gilt insbesondere für 'next-generation access networks'. Investitionsentscheidungen müssen unter Unsicherheit über die Zeit hinweg getroffen werden. Diese Arbeit entwickelt einen Modellrahmen, innerhalb dessen Unsicherheit über die zukünftige Marktentwicklung, Risikoaversion der Marktteilnehmer sowie Investitionsentscheidungen im Zeitablauf explizit berücksichtigt. In einem ersten Schritt werden unterschiedliche Zugangsbestimmungen hinsichtlich der Investitionsanreize unter der Hypothese bewertet, dass der inkrementelle Wert der Investition gegenüber dem bestehenden Netz unsicher ist. In einem zweiten Schritt wird Risikoaversion der Netzbetreiber eingeführt. Hierbei wird bestimmt, wie die Struktur der Zugangspreise das Risikoprofil des investierenden und des Zugang suchenden Netzbetreibers bestimmt. In einem dritten Schritt werden Investitionen im Zeitablauf betrachtet und Implikationen der zeitlichen Struktur der Zugangspreise abgeleitet.

Schlagwörter: NGA, Investitionen unter Unsicherheit, Zugangspreise, Zugangsregulierung, Telekommunikation 


\title{
Investment under Uncertainty and Regulation of New Access Networks ${ }^{1}$
}

\author{
Roman Inderst 2 \\ Goethe-University Frankfurt \\ Martin Peitz 3 \\ University of Mannheim
}

first version: January 2011, this version March 2013

\begin{abstract}
Contractual and regulatory provisions for access affect incentives to invest in an upgraded network and, in particular, a next-generation access network. Investment decisions are made under uncertainty and have to be made over time. This papers provides a framework for taking uncertainty, risk aversion, and the timing of investment explicitly into account. First, it evaluates various access price policies in a framework in which the incremental value over the legacy network is uncertain. Second, introducing risk aversion, the access price structure turns out to be critical for the risk profile of the investing telecom operator and of the access-seeking alternative operator. Third, some implications of the time structure of access payments are derived.
\end{abstract}

Keywords: NGA, investment under uncertainty, access price rule, telecommunications

JEL-Classification: L1, L5

1 This paper is part of a large project for the German Ministry of Economics. A German-language and more-policy-oriented version of this research can be found in Inderst et al. (2012), which draws heavily on the present paper. Financial support from the German Ministry of Economics is gratefully acknowledged.

2 Johann Wolfgang Goethe University Frankfurt. E-mail: inderst@finance.uni-frankfurt.de.

3 Corresponding author: Department of Economics, University of Mannheim, 68131 Mannheim, Germany, email: martin.peitz@gmail.com, also affiliated with CEPR, CERRE, CESifo, MaCCI and ZEW. 


\section{Introduction}

Uncertainty about the success of an investment is arguably an important obstacle to the roll-out of fibre networks and other investments to upgrade an existing network. In particular, investments in next-generation access networks are associated with highly unpredictable future profits after making the investment. Policy makers have acknowledged this. In particular, the European Commission has observed that Europe lags behind the U.S. and Asia in such developments. The European Commission states:

There are several reasons, the most evident being the uncertain commercial viability of substantial network investments, due to prevailing investment models and the EU market structure. But also because of doubts about consumers' short-term willingness to pay more for higher speeds, as new high value-added digital content and services are not necessarily available yet throughout the EU. $\ldots 4$

This quote also highlights the importance of the uncertain development of complementary services made feasible by the new technology, as well as consumers' uncertain take-up of these services. An investment's profitability also depends, more generally, on the speed of market penetration since the investment, for the most part, constitutes a sunk cost, and an efficient roll-out relies on quick take-up. ${ }^{5}$ While there may be immediate revenues, profitability depends crucially on a continuous revenue stream over a long period. This long time horizon tends to further increase the uncertainty that the investing party faces.

Uncertainty over the key parameters of a firm's decision and its implications also plays an important role in the modern theory of regulation. A large part of the literature considers private information held by the party that is subject to regulation. ${ }^{6}$ For example, a regulator may have to set access prices without perfectly knowing the cost function of the regulated firm. While this is a relevant issue, this paper will abstract from private information of this type. We focus, instead, on uncertainty about a new technology's potential. This uncertainty has direct implications for the way that particular regulatory interventions affect market outcomes. For instance, the regulator may oblige the investing network operator to grant access at a given fixed fee. Whether other firms will make use of this possible access is uncertain, as it depends on the utility that consumers de-

4 Communication from the Commission to the European Parliament, the Council, the European Economic and Social Committee and the Committee of the Regions, The Digital Agenda for Europe - Driving European growth digitally, December 18, 2012, COM(2012) 784 final, page 8.

5 A high degree of uncertainty may already have been relevant at an earlier point in the development of local telecommunications networks. Pindyck (2007) emphasizes the relevance of uncertainty for such investments. However, some economists have challenged the general presumption that the network operator suffers from uncertainty; see Economides (2002).

6 For instance, Armstrong and Sappington (2007) provide an overview. 
rive from additional services associated with the investment. Thus, at the moment of making the investment, its overall value depends both directly on its success with consumers and indirectly on the possibility of passing on costs to other firms. The extent to which this is possible depends, in turn, on the access regulation that is in place. This issue does not arise without uncertainty.

A key aspect in our analysis is the non-investing firm's decision of whether or not to use the new technology under the prevailing access conditions. More generally, it has to decide the extent and the timing of offering the new technology to its consumers. Efficient regulation increases the probability that another firm will use the new technology early (here, we abstract from limited capacity). If firms use the new technology symmetrically, then competition in each downstream market is intense. This tends to lead to a high consumer surplus and only small allocative inefficiencies, measured by a small deadweight loss. This observation hints at an important disadvantage of fixed access fees, which are optional in the sense that access-seeking firms decide after the investment whether they are interested in accessing the new technology. The inefficiency may be reduced if the payment for access depends on the quantity of the access product that the access-seeking firm demands. However, introducing such variable access fees may lead to higher retail prices, on average. Thus, we find a trade-off between fixed and variable optional access fees. This trade-off might be attenuated by using general, non-linear tariffs. Also, from a social perspective, access fees that condition on relevant changes in market characteristics may be preferable to those that do so only indirectly.

As an extreme alternative, we also discuss a fixed non-conditional upfront fee, which removes the optionality of the access payment. The marginal price of obtaining access can then be set equal to the corresponding marginal costs. With this regulatory policy, however, one should bear in mind several caveats. Most obviously, if, at the moment of the investment, the access-seeking firm does not yet exist, the mechanism is simply not applicable. Further, the fixed fee should be based on the expected demand of the access-seeking firm, if this is feasible. A policy that applies a fee to all firms indiscriminately will not allow small firms to operate profitably in the market. Finally, an induced high degree of competition, while being desirable from an ex post perspective, could lead to underinvestment or inefficiently postponed investment from a social welfare perspective. Apart from the access price rules mentioned above, alternative solutions exist. For instance, an access-seeking firm may acquire the option to obtain access under predefined conditions. This allows for a combination of optional and non-optional fixed payments. Also, the contract or the regulatory rule may specify certain quantities for which preferential access can be obtained by making a non-optional upfront payment. When a wait-and-see strategy becomes more attractive for the access-seeking firm, it may use the new technology rather late, to the detriment of social welfare. Then, the time structure of the access tariff may be used to improve dynamic efficiency by providing incentives for earlier and more-intensive use of the new technology. We discuss when non- 
linear tariffs based on access levels and front-loaded access tariffs can increase welfare.

As a final contribution, we discuss the optimal allocation of risk between firms. The allocation of risk depends, for example, on the degree to which the access of the noninvesting firm remains optional and on the use of fixed fees versus incremental, usagebased payments. The allocation of risk may matter for efficiency, in particular, when firms appear to be averse even with respect to idiosyncratic risk-e.g., as they have limited access to capital markets.

The rest of this paper is organized as follows. Section 2 introduces the formal framework. Section 3 considers firms' optimal investment and contractual choice, as well as the impact of various access policies. Section 4 introduces optimal risk-sharing, while Section 5 provides an extension to a dynamic investment path. Section 6 concludes.

Guide to the literature: This paper complements the analysis of Inderst and Peitz (2012a, 2012b), which investigates firms' incentives to invest in a new technology when starting with an old technology (i.e., a legacy network). Others also have looked at this issue. For a recent survey, see Cambini and Jiang (2009). A recent addition to the literature is Nitsche and Wiethaus (2011), a welfare assessment of the effect of access rules on the incumbent's investment incentives. Other recent work includes Brito, Pereira and Vareda (2012) and Bourreau, Cambini and Dogan (2012), which consider the migration from old to new technology and the role of access rules. Less closely related are studies that investigate the effects of access prices on the outcome of dynamic investment races (e.g., Hori and Mizuno, 2006; Vareda and Hoernig, 2010).

The contribution of this paper is to explore the role of uncertainty in investments and retail prices, distinguishing among various types of access contracts. We distinguish, in particular, among access contracts that are signed prior to investment and commit to payments (co-investments); those that are signed prior to investment but in which payments by one firm are optional; and those that are signed after a firm has made the investment. Our paper also complements Bourreau, Cambini, and Hoernig (2013), which looks at co-investment under uncertainty in a setting with a continuum of regional markets. ${ }^{7}$

\section{The model}

This paper builds on Inderst and Peitz (2012a). In the main text, we adopt a reducedform presentation; in the Appendix, we develop a specific model that satisfies all of our

7 Since Bourreau, Cambini, and Hoernig (2012) allow for perfect price discrimination across regional markets, a model with a single market extends to a market with a continuum of regional markets in a straightforward way, as long as costs are linear in the number of markets. However, they postulate that these costs are strictly convex, which makes the analysis of coverage meaningful. 
reduced-form assumptions in the main text and, thus, provides a micro-foundation of our approach.

\subsection{Model under certainty}

We consider a duopoly model with firms $i=1,2$. Firm 1 is the only firm that may undertake an investment. In an otherwise symmetric environment, we consider markets in which network duplication is not economically feasible-i.e., a situation of natural monopoly with respect to the new technology. We largely abstract from other asymmetries that may contribute to an incumbency advantage (for a focus on asymmetries, albeit in an environment with certainty, we refer the reader to Inderst and Peitz, 2012b). The ensuing price competition between operators is explicitly modeled in the Appendixsee, also, Inderst and Peitz (2012a). Firm $i$ 's profits are denoted by $\pi_{i}\left(u_{1}, u_{2}\right)$ where $u_{i}$ denotes the gross utility delivered by firm $i$.

Absent additional investments, we postulate that both firms offer the same service; they both have access to a legacy network. As a measure of network quality and, thus, consumer gross utility, we have $u^{O}$. Superscript $O$ stands for the old technology. Without any investment, firms obtain profits $\pi_{1}\left(u^{O}, u^{O}\right)$ and $\pi_{2}\left(u^{O}, u^{O}\right)$, respectively.

In Inderst and Peitz (2012a), we consider an investment that can be made at cost $I_{i}$ and that increases the quality and associated utility from $u^{O}$ to $u^{N}>u^{O}$ (where superscript $N$ stands for the new technology). The investment can be made by one or both firms. To offer services with this quality for all consumers, it is not necessarily required that both operators invest. If the investing firm grants access to the other firm, both firms can offer the high quality available with the new technology. In the following, we are interested mainly in the case in which exactly one operator-i.e., operator $i=1-$ invests.

If the other firm $i=2$ does not obtain access, profits (gross of the investment cost for firm 1) are $\pi_{1}\left(u^{N}, u^{O}\right)$ and $\pi_{2}\left(u^{N}, u^{O}\right)$. Note that we postulate that firm 2 continues to have access to the old technology, although this may not be true if that access is through, for instance, an unbundling agreement, and the interconnection points are bypassed when investing in the new technology. We elaborate on this issue in Inderst and Peitz (2012b) but abstract from it in this paper. The difference from the status quo is that firm 1 offers the better technology with its additional services such that $u^{N}>u^{O}$. Thus, firm 1 obtains a higher gross profit than in the status quo, $\pi_{1}\left(u^{N}, u^{O}\right)>\pi_{1}\left(u^{O}, u^{O}\right)$, while firm 2 obtains a lower profit, $\pi_{2}\left(u^{N}, u^{O}\right)<\pi_{2}\left(u^{O}, u^{O}\right)$. Subtracting the investment cost $/$, firm 1 makes a net profit of $\pi_{1}\left(u^{N}, u^{O}\right)-I$.

If, however, firm 2 obtains access at marginal costs to firm 1's high-quality network, profits gross of any investment costs and transfers are $\pi_{1}\left(u^{N}, u^{N}\right)$ and $\pi_{2}\left(u^{N}, u^{N}\right)$. 
Profits depend on the access agreement or access regulation, as we will elaborate on below.

\subsection{Modeling uncertainty}

We introduce uncertainty about the value of the investment by making $u^{N}$ a random variable. This reflects the uncertainty about the availability and quality of new services for which the new technology is required. Initially, firms have to form expectations about $u^{N} ;$ the expected value is denoted by $E\left[u^{N}\right]$.

We postulate that $u^{N}$ can take any value between $u^{O}$ and some upper bound $\bar{u}$. If $u^{N}=u^{O}$, consumers do not derive any additional utility from using the new technology. Furthermore, we postulate that variable costs are the same for the old and new technologies. Hence, for any strictly positive difference $u^{N}-u^{O}$, the new technology will be used if available. Cost differences could, however, be easily incorporated.

If firm 1 has invested in and uses the new technology while restricting access, its expected net profit is

$$
E\left[\pi_{1}\left(u^{N}, u^{O}\right)\right]-I
$$

When firm $i=2$ does not obtain access and, thus, continues to use the old technology $u_{2}=u^{O}$, its expected profit is $E\left[\pi_{2}\left(u^{N}, u^{O}\right)\right]$. If access is granted or if investment costs are shared, profits will be different. These profits will be analyzed in the following section when we consider various alternative regulatory policies.

\section{Risk-neutral firms and investments}

In this section, we analyze a market in which firms are risk-neutral. For simplicity, we also abstract from the timing of the investment and the dependence of profits on the timing decision. Thus, only the levels of investment costs and expected profits have to be considered.

Looking at both access-seeking and access-granting firms, we investigate the role of uncertainty for the evaluation of different regulatory policies and contracting environments. We distinguish between optional and non-optional payments for access. With regard to the former, the access-seeking firm can decide whether to seek access after the investment (and after the uncertainty has been resolved). With regard to the latter, the access-seeking firm enters a binding agreement before undertaking the investment and cannot simply walk away when the market environment turns out to be unfavorable. 
The second distinction concerns the access price structure with linear tariff and fixed tariff as extreme cases and non-linear price structures as intermediate cases.

\subsection{Non-optional fixed fees}

Our simplest benchmark case is a non-optional fixed access price $F$ that the accessseeking firm has to pay to the access-granting firm (in addition to a marginal usage fee equal to marginal cost). Thus, $F$ implements a particular cost sharing determined by regulation or through negotiations between the two firms. More precisely, the accessseeking firm contributes $F$, and the access-granting firm contributes $I-F$. The fixed payment may depend on the expected usage of the new technology and on the bargaining power of the two firms. We will return to this issue below.

If the investment is made and both firms use the new technology, profits are $\pi_{i}\left(u^{N}, u^{N}\right)$. The equilibrium then implements the same allocation as in a situation in which both firms invest, but with the difference that the duplication of fixed costs is avoided.

\section{Investment incentives}

We next address the question of whether the investment will be undertaken. Here, we distinguish between two scenarios. In the first scenario, the investment is not profitable when firm 2 continues to use the old technology. In the second scenario, the contrary holds. In the first scenario, when the two parties reach no agreement, no investment takes place. In the second scenario, firm 1 will invest regardless.

Scenario 1 prevails if

$$
E\left[\pi_{1}\left(u^{N}, u^{O}\right)\right]-I<\pi_{1}\left(u^{O}, u^{O}\right) .
$$

Both firms agree with the cost sharing if

$$
\begin{gathered}
E\left[\pi_{1}\left(u^{N}, u^{N}\right)\right]-(I-F) \geq \pi_{1}\left(u^{O}, u^{O}\right) \text { and } \\
E\left[\pi_{2}\left(u^{N}, u^{N}\right)\right]-F \geq \pi_{2}\left(u^{O}, u^{O}\right) .
\end{gathered}
$$

This can be satisfied only if industry profits satisfy

$$
E\left[\pi_{1}\left(u^{N}, u^{N}\right)+\pi_{2}\left(u^{N}, u^{N}\right)\right]-I \geq E\left[\pi_{1}\left(u^{O}, u^{O}\right)+\pi_{2}\left(u^{O}, u^{O}\right)\right] .
$$

Otherwise, one cannot find a contract with cost sharing $(I-F, F)$ that is agreeable to both firms. Whether inequality (4) holds depends on the required investment level $I$ and the likelihood that high levels of $u^{N}$ are realized. It also depends on how the new technology affects total demand and competition. The basic model developed in the Appen- 
dix has the feature that total industry profits are independent of the technology in use, which implies that inequality (4) is not satisfied in that model. Thus, demand expansion or less competitive pressure as a result of the investment is required for inequality (4) to hold.

More-intense competition makes it more likely that we are in scenario 2, satisfying

$$
E\left[\pi_{1}\left(u^{N}, u^{O}\right)\right]-I \geq \pi_{1}\left(u^{O}, u^{O}\right) .
$$

Here, the investment is profitable for firm 1 if the new technology is not shared with firm 2. With more-intense competition, demand reacts more strongly to price changes (i.e., there is a strong business-stealing effect), and firm 1 can play out its technological advantage. With intense competition and a low elasticity of total demand-so that there are no benefits from market expansion that can be shared-firm 2 will neither obtain access nor duplicate the investment. These findings are in line with what is obtained under certainty and, thus, do not merit the statement of a formal result.

\section{Cost sharing and usage}

We next address the question of how costs should be shared, provided that there is an agreement, and how uncertainty impacts the expected profits under such cost-sharing rules.

A reasonable rule for distributing the investment cost between the two firms is to base cost sharing on the expected usage of the technology-i.e., the expected number of subscribers for each firm. Given the realization $u^{N}$, we denote the number of subscribers of the two firms by $q_{1}\left(u^{N}, u^{N}\right)$ and $q_{2}\left(u^{N}, u^{N}\right)$. (For a particular specification of these demand functions, we again refer the reader to the Appendix.) Denoting expected demand by $E\left[q_{1}\right]$ and $E\left[q_{2}\right]$, we obtain cost sharing according to fully distributed costs

$$
F=\frac{E\left[q_{1}\right]}{E\left[q_{1}\right]+E\left[q_{2}\right]} I
$$

and

$$
I-F=\frac{E\left[q_{2}\right]}{E\left[q_{1}\right]+E\left[q_{2}\right]} I
$$

for the two firms.

We note that this cost-sharing rule does not necessarily satisfy the participation constraint (3) in scenario 1, even though a different distribution might exist that does satisfy it. More precisely, we can always find such a distribution $\left(F^{\prime}, I-F^{\prime}\right)$ if inequality (4) is satisfied, even if (3) is not satisfied for the rule specified in (6). 


\subsection{Optional fixed fees}

We continue to consider access provision for a fixed fee. In contrast to the previous subsection, we now postulate that firm 2 can opt out after undertaking the investment and after $u^{N}$ was realized. This means that the non-investing firm makes its decision about seeking access after the uncertainty has been resolved (while the optional contract is signed prior to the realization $u^{N}$ ).

\section{Inefficiency after an investment}

Making the demand for access conditional on the realization of $u^{N}$ introduces a possible inefficiency. We note that, given the investment in the new technology, it is always socially efficient that both firms use the new technology. However, it is not necessarily privately optimal for firm 2 to obtain such access because the conditions of access are not favorable for it. Paying the fixed access fee $F$ is optimal for firm 2 only if

$$
\pi_{2}\left(u^{N}, u^{N}\right)-F \geq \pi_{2}\left(u^{N}, u^{O}\right) .
$$

We consider markets in which $\pi_{2}\left(u^{N}, u^{N}\right)$ is weakly increasing in $u^{N}$ (see the Appendix for details): This means that profits do not decrease if the new technology and the associated services turn out to be more attractive for consumers. By contrast, if firm 2 continues to use the old technology, its profit $\pi_{2}\left(u^{N}, u^{O}\right)$ is postulated to be decreasing in the attractiveness of the new technology $u^{N} .^{8}$ Since the left-hand side of (7) is weakly increasing in $u^{N}$ and the right-hand side is decreasing, there is, at most, one intersection point. With the appropriate boundary behavior, there is a unique critical value $u^{N}=u^{*}$ at which (7) is satisfied with equality. For all realizations $u^{N}>u^{*}$, firm 2 will seek access at price $F$, while for all realizations $u^{N}<u^{*}$, it prefers not to use the new technology. This leads to an inefficiency in the use of the new technology:

Result 1: With an optional fixed access price greater than zero, a given investment is inefficiently used because the firm that may want to ask for access decides not to do so if the new technology turns out to be not sufficiently superior to the old technology.

The optionality that firm 2 enjoys has the consequence that after a bad realization of $u^{N}$, firm 2 continues to use the old technology, and only firm 1 , which has sunk its investment cost, uses the new technology, although it would be socially efficient if both firms did. For all realizations $u^{N}<u^{*}$, firm 1 is the only firm that offers the new technology. This tends to give rise to an additional inefficiency, as the resulting asymmetry of firms may reduce competition. Thus, consumer surplus also may suffer.

8 We also note that this property is not always satisfied: This may happen if consumers are sufficiently heterogeneous with respect to their preference for the old versus the new technology. With such vertical differentiation, the firm with the old technology may benefit if the new technology becomes more attractive, as this reduces competition by increasing differentiation. 
The investing firm shares part of the investment cost with positive probability—namely, with the probability that $u^{N}$ is greater than $u^{*}, \operatorname{Pr}\left[u^{N} \geq u^{*}\right]$. Thus, the expected contribution to costs is

$$
f=F \cdot \operatorname{Pr}\left[u^{N} \geq u^{*}\right]
$$

To share a particular fraction of the total investment cost, it becomes necessary to increase $F$ beyond the level with a non-optional fee. However, the larger $F$ is, the larger is the critical value $u^{*}(F)$, which is implicitly defined by $\pi_{2}\left(u^{*}, u^{*}\right)-F=\pi_{2}\left(u^{*}, u^{O}\right)$. This again pushes up the level $F$ that is necessary to realize a given $f$, and so on. Ultimately, it may, then, not be feasible at all to share costs in this way.

\section{Investment incentives}

Our preceding analysis has immediate implications for firm 1's investment incentives. In particular, it may not be possible with optional fees to provide sufficient investment incentives for firm 1. If firm 2 does not use the new technology for realizations $u^{N} \leq u^{*}$, this also reduces the rent that the investing firm can potentially extract. (Also, the intensity of competition matters; we return to this issue below.)

Due to the optionality to access, firm 2 will necessarily obtain a positive net surplus. This implies that it is impossible for firm 1 to extract all the rents that are generated through the investment. More precisely, firm 2 is, at $u^{N}=u^{*}$, indifferent about whether it should pay $F$ and obtain access to the new technology. For any realization $u^{N}>u^{*}$, it does strictly better by obtaining access. Thus, the expected rent is strictly positive. There is, however, a countervailing force. So far, we have considered only rents at the wholesale level of firm 1 and have not evaluated the consequences for downstream competition. In particular, for all realizations $u^{N}<u^{*}$, firm 1's market power increases relative to an environment in which firm 2 always has access to the new technology; in a sense, a high fixed fee partially forecloses the market for firm 2 . This leads to higher downstream profit. If symmetric competition is intense and the price elasticity of total demand low, firm 1 might actually realize higher profits if it does not share the technology, even though it foregoes additional wholesale revenues.

\subsection{Ex-post contracts with a fixed fee}

So far, we have restricted ourselves to a conceptual discussion of simple ex-ante and ex-post (optional) fixed-fee contracts. In what follows, we discuss how these parameters are determined with and without regulation and make the respective contractual choices more flexible. Inderst and Peitz (2012a) distinguish between ex-ante and ex-post contracts. The latter are negotiated and signed only after the investment is made. In the 
setting with certainty, the range of investment costs for which there is investment in the new technology is expanded by allowing for ex-ante contracting. Introducing uncertainty in this paper, it is important to determine whether the contracting stage comes before or after $u^{N}$ has been realized. First, we abstract from regulation and also suppose that $u^{N}$ is already known at the contracting stage. With ex-ante uncertainty, ex-post contracts then allow for adjustments to the prevailing market conditions, which tend to reduce or even remove inefficiencies in the usage of the new technology. Subsequently, we introduce regulation.

\section{Flexible cost sharing}

Suppose that, after the investment and after the realization of $u^{N}$, firm 1 makes a takeit-or-leave-it offer to firm 2 . Firm 1 then sets the fixed fee

$$
F\left(u^{N}\right)=\pi_{2}\left(u^{N}, u^{N}\right)-\pi_{2}\left(u^{N}, u^{O}\right) .
$$

Hence, the investing firm extracts all the value added to firm 2 as a result of obtaining access to the new technology. Access is provided whenever industry profits increase due to access provision:

$$
\pi_{1}\left(u^{N}, u^{N}\right)+\pi_{2}\left(u^{N}, u^{N}\right) \geq \pi_{1}\left(u^{N}, u^{O}\right)+\pi_{2}\left(u^{N}, u^{O}\right) .
$$

By the preceding remarks, for this inequality to hold, at least one of two properties has to be satisfied: a demand expansion effect due to the new technology being made available to firm 2 or competition becoming less intense with a better technology. Otherwise, firm 1 will not grant access under conditions that firm 2 will accept, as we will discuss below. We note that it is possible, in general, that inequality (8) holds only on a subset of $\left[u^{O}, \bar{u}\right]$.

Since the fixed fee has now-through ex-post contracting-indirectly become a function of $u^{N}$, this "more-flexible" fee $F\left(u^{N}\right)$ can increase efficiency relative to an unconditional ex-ante fee. With a take-it-or-leave-it offer, firm 1 can fully extract the increase in firm 2 's profit when making the new technology available to its competitor. Its profit is $\pi_{1}\left(u^{N}, u^{N}\right)+\left[\pi_{2}\left(u^{N}, u^{N}\right)-\pi_{2}\left(u^{N}, u^{O}\right)\right]$. This implies that firm 1 's expected profits from the investment are larger than in the setting in which access cannot be provided. Suppose that inequality (9) holds for all feasible $u^{N}$. Then, for the investment to be made, the expected profit from investing must be larger than the equilibrium profit when not investing,

$$
E \pi_{1}\left(u^{N}, u^{N}\right)+\left[E \pi_{2}\left(u^{N}, u^{N}\right)-E \pi_{2}\left(u^{N}, u^{O}\right)\right]-I \geq \pi_{1}\left(u^{O}, u^{O}\right) .
$$

This defines a critical investment level above which firm 1 does not invest. We can now compare the investment incentives with ex-post contracts to the ones with non-optional 
ex-ante contracts. If firm 1 makes a take-it-or-leave-it offer, and we are in scenario 1 (cf. above), firm 1 's expected profit when investing is

$$
E \pi_{1}\left(u^{N}, u^{N}\right)+\left[E \pi_{2}\left(u^{N}, u^{N}\right)-\pi_{2}\left(u^{O}, u^{O}\right)\right]-I .
$$

Since $\pi_{2}\left(u^{O}, u^{O}\right)>E \pi_{2}\left(u^{N}, u^{O}\right)$, the expression in (11) is smaller than the left-hand side of (10). This implies that there is a larger range of investment costs such that firm 1 invests under ex-post contracts. The logic is as follows: In scenario 1 and with exante contracts, firm 2 knows that if it rejects the proposed contract, there will be no investment and its profit will be $\pi_{2}\left(u^{O}, u^{O}\right)$. In contrast, with ex-post contracts, firm 1 has already invested. Therefore, rejecting the proposed ex-post contract implies that firm 1 still uses the new technology, with the effect that firm 2 will earn only $\pi_{2}\left(u^{N}, u^{O}\right)$. Thus, with ex-post contracts, firm 2 is in a weaker position. ${ }^{9}$

Result 2: Suppose that with ex-post contracts prescribing a fixed fee, the investing firm has all bargaining power. Then, this can provide stronger investment incentives than under unconditional ex-ante contracts with a fixed fee.

\section{Negotiations, hold-up and investment incentives}

The fixed fee $F$ in (8) has been derived under the assumption that firm 1 has all the bargaining power and can, therefore, extract the maximal rent from firm 2 . Yet another possibility is that there is a fixed sharing rule based on the two firms' bargaining power: There is Nash bargaining over the gain from access to the technology, so that the surplus gained is shared in equal parts. The values of the outside options of the two firms are $\pi_{i}\left(u^{N}, u^{O}\right), i=1,2$, respectively. The surplus is

$$
S=\left[\pi_{1}\left(u^{N}, u^{N}\right)+\pi_{2}\left(u^{N}, u^{N}\right)\right]-\left[\pi_{1}\left(u^{N}, u^{O}\right)+\pi_{2}\left(u^{N}, u^{O}\right)\right] .
$$

To implement equal surplus sharing, the fee $F\left(u^{N}\right)$ must satisfy

$$
\pi_{1}\left(u^{N}, u^{N}\right)+F\left(u^{N}\right)=\pi_{1}\left(u^{N}, u^{O}\right)+S / 2 .
$$

A hold-up problem may arise in this case: The investing firm has to bear all the investment costs, which, when negotiations take place, will be sunk and, thus, will not be considered during the negotiations. This reduces firm 1 's incentives to invest.

Such a hold-up-problem does not arise under ex-ante contracting (i.e., prior to negotiations that take place prior to the investment) or a corresponding regulation of the fee $F$. Comparing the solution under ex-post bargaining with the (optional) ex-ante version, we see the following trade-off: On the one hand, through a flexible adjustment $F\left(u^{N}\right)$, the

9 Inderst and Peitz (2012a) do not obtain this result, as they focus on situations in which inequality (9) is not satisfied. However, it can also be shown under certainty. 
ex-post contract permits a more efficient outcome with respect to usage. This leads to higher industry profits and, thus, has a positive impact on investment incentives. On the other hand, efficiency may suffer due to the hold-up problem.

What this discussion leaves unanswered, however, is the question of whether moreflexible ex-ante contracts (or corresponding regulation) could sufficiently improve on the ex-ante contracts considered above. We turn to this issue in the following subsection.

\subsection{Flexible ex-ante regulation and flexible ex ante contracts}

In Subsection 3.3, we pointed out that there are stronger investment incentives if the firm that decides whether to invest has all the bargaining power. This holds under both certainty and uncertainty. If the firm does not have all the bargaining power, the picture is more complicated because of a hold-up problem for the investing firm. We also showed that ex-post contracts are a good instrument for extracting surplus for the investing firm in the presence of uncertainty, as they can be conditioned on the realization of the random variable. However, in principle, ex-ante contracts can be made more flexible too, allowing them to condition on the realization of the random variable. With expost contracts, it is required only that the realization $u^{N}$ is observable. For ex-ante contracts to directly condition on this realization, it is required that $u^{N}$ is not only observable, but also verifiable. The simplest case is, thus, that where $u^{N}$ can be directly contracted upon, e.g., via a fee. To avoid allocative inefficiencies, given the considered optionality and a reduction of investment incentives, this fee should be increasing in $u^{N}$. If the market performs better than expected (high $u^{N}$ ), the fraction of the investment cost $I$ covered through $F$ increases. This implies that the investing firm has to finance a larger part of the investment cost if the realization $u^{N}$ turns out to be low. Alternatively, if one wants to condition the fee on the realized profits of the access-seeking firm, a possible rule could take the following linear form:

$$
F\left(u^{N}\right)=a \pi_{2}\left(u^{N}, u^{N}\right)
$$

i.e., the access-seeking firm has to pay a fraction $a$ of its gross profit $\pi_{2}\left(u^{N}, u^{N}\right)$ after $u^{N}$ has been realized. (This involves the ad hoc assumption that firms do not strategically react and, thus, distort competition in the product market to manipulate the fee payment. We turn to the issue of distorted competition in a related setting below.) We observe that such a linear rule cannot ensure the efficient adoption of the new technology. That would require that the fee is 0 when $u^{N}=u^{O}$. (However, a modified rule $F\left(u^{N}\right)=a\left[\pi_{2}\left(u^{N}, u^{N}\right)-\pi_{2}\left(u^{O}, u^{O}\right)\right]$ would satisfy this property.) A fee that does not directly condition on $u^{N}$, but on profits (as in equation (12)), is no longer a fixed payment. It depends (non-linearly) on the chosen quantities $q_{1}$ and $q_{2}$ (number of subscribers). In the next subsection, we consider, instead, a fee that depends linearly on these quantities. 


\subsection{Usage-dependent surcharge: Cost sharing with a surcharge}

A special case of a contingent contract is an access fee that linearly depends on usage-i.e., the number of subscribers. The access price per subscriber is denoted by $w$. Thus, firm 2 pays for access $w q_{2}$. As in the previous subsection, the access price per subscriber can be determined ex-post-i.e., after the investment has been made or exante. Absent any fixed payment, such a payment is always optional, as firm 2 can avoid any payment to firm 1 by avoiding enrolling subscribers to the new technology. ${ }^{10}$

\section{Distorted competition}

If both firms use the new technology-i.e., $u_{i}=u^{N}$-and if the access price depends on the number of users and is greater than the marginal cost, firm 2 faces a higher marginal cost than firm 1. In the linear specification, this is the case if $w$ is greater than the cost of providing the new technology to an additional consumer. Following the idea of cost sharing according to usage, in order to determine the level of the access price $w$, one has to make sure that, in expectation, the access-seeking firm pays the fraction of the investment cost for access, which corresponds to the fraction of access contracts it signs. ${ }^{11}$

Since there is a positive margin in the access market, competition is distorted in the following way: Firm 2 faces a higher marginal cost, leading to higher prices and a weakly smaller quantity. Firm 1 faces a higher opportunity cost: While a lower retail price increases its own subscriber number and, thus, locally, its retail revenue, it also reduces the number of units sold by the competitor and, thus, firm 1 's revenue in the access market. Therefore, both firms have little incentive to set low prices. In the special case of constant total demand, there is a one-to-one pass-through of access prices into retail prices (see de Bijl and Peitz, 2006). Hence, a linear access rule $w q_{2}$ leads to less competition and, thus, lower consumer welfare. For elastic total demand, there is also a deadweight loss (following from a lower equilibrium quantity).

However, as discussed in Inderst and Peitz (2012a), comparing a fixed fee $F$ with a price per user $w$ can lead to a trade-off between allocative efficiency and investment incentives. The trade-off arises as follows: By setting $w$ above marginal costs, the allocative efficiency is negatively affected if total demand is not constant and is not affect-

10 Note that we consider the choice of technology as a discrete choice-i.e., we do not allow a firm to offer a menu of contracts with different technologies to consumers. In the model developed in the Appendix, all users have the same preferences over different technologies, which justifies our discretechoice assumption. However, more generally, users may have differences in taste with respect to the possible technologies, which would make the discrete-choice assumption more restrictive.

11 The calculation is more involved than the calculation of $F$ in (6) since the expected quantities of $q_{1}$ and $q_{2}$ have to reflect the adoption probability. 
ed if total demand is constant. In any case, industry profits increase, which tends to increase the expected profitability of the investment since the investing firm might be able to appropriate a large fraction of the increase in industry profits. ${ }^{12}$ By contrast, with a fixed fee, industry profits are constant. In the special case of constant total demand, investment incentives are stronger with linear access tariffs. With price-dependent demand, the analysis is less straightforward; however, if demand is not very sensitive to price, the abovementioned trade-off prevails.

\section{Efficient adoption of the new technology}

Unlike the analysis with uncertainty in Inderst and Peitz (2012a), there is an efficiency argument in favor of a linear access price $w$ relative to a fixed fee $F$. Since the total access payment $w q_{2}$ positively depends on quantity and, thus, on market conditions, the adoption of the new technology by firm 2 becomes more likely. ${ }^{13}$

Result 3: Uncertainty over $u^{N}$ makes the adoption of the new technology by firm 2 more likely under a linear access fee than under a fixed fee.

Within our framework, this is seen as follows: Depending on the access price $w$ and the expected quantity $q_{i}\left(u^{N}, u^{N}\right)$, at $u^{N}$, firm 2 asks for access if

$$
\pi_{2}\left(u^{N}, u^{N} ; w\right)-w \cdot q_{2}\left(u^{N}, u^{N}\right) \geq \pi_{2}\left(u^{N}, u^{O}\right) .
$$

Here, we have introduced the notation $\pi_{2}\left(u^{N}, u^{N} ; w\right)$ to capture profits gross of the payment for access to the new technology. They still depend on $w$ since its level affects competition in the retail market. Firm 2 's profits when using the old technology are on the right-hand side of (13), which are decreasing in $u^{N}$.

Since firm 2 chooses its demand for access by maximizing its profits, the right-hand side of (13) is typically strictly increasing in $u^{N}$ (for given $w$ ). Thus, with a linear access tariff, the access seeker's profits are positively aligned with market conditions (higher $\left.u^{N}\right)$. Thus, from (13), there is a cutoff $u^{*}$ such that access is requested if $u^{N} \geq u^{*}$. A key observation is that with a linear access tariff, firm 1 obtains larger access revenues for higher realizations of $u^{N}$. Therefore, to cover a certain fraction of costs in expectation, the payment for a lower $u^{N}$ can be lower. This reduces the cutoff $u^{*}$ below which firm 2 does not seek access (relative to an optional fixed fee). This has the welfareincreasing property that firm 2 uses the new technology more "frequently" and works

12 A caveat is in order: Absent the additional instrument of a fix fee (or some other non-linear access tariffs), it is possible that while a higher $w$ reduces the intensity of competition, incremental profits (including access revenues) of firm 1 generates lower profits than a fix fee, the reason being that $w$ may allow firm 1 to appropriate only small part of the profit increase of firm 2.

13 If an access price per subscriber is reached through negotiations instead of through regulation, the danger of market foreclosure tends to be reduced (in particular, if the access tariff also includes a fixed fee). Recall that investments such that firm 1 does not grant access happen only if industry profits with joint use are less than industry profits when firm 2 does not obtain access. 
against the negative effect of a higher access price $w$ on competition between the two firms.

\section{Non-linear usage prices}

By definition, a linear payment for access with the access price $w$ has the property that the marginal cost to enroll an additional user is constant for firm 2 . An alternative is to allow for price discrimination between different demand profiles in the access market by, for example, allowing quantity discounts for firms that enroll a large number of subscribers. This provides incentives to use the access product to a greater extent.

In particular, $w$ may depend on $q_{2}$ such that the price per subscriber is decreasing in $q_{2}$ : Denoting this price by $w\left(q_{2}\right)$, this function decreases in $q_{2}$. Given a realization $u^{N}$ (since quantities depend on total demand in the retail sector and, thus, on $u^{N}$ ), the deadweight loss would become smaller. Both firms would have an incentive to increase their quantities-for firm 1, as the marginal price it obtains from granting access declines, which provides incentives to keep the competitor small; and for firm 2, as the marginal opportunity cost of increasing its quantity falls. ${ }^{14}$

Such a non-linear access price may run counter to the goal of reducing the payment by the access-seeking firm in the case of bad realizations of $u^{N}$. This makes it possible that the resulting cutoff $u^{*}$ is lower and, hence, that both firms use the new technology. This, again, is due to the property that a low realization of $u^{N}$ results in low quantities $q_{i}\left(u^{N}, u^{N}\right) .15 \mathrm{~A}$ higher realization of $u^{N}$ increases the average price paid for access, as long as $w\left(q_{2}\right)$ is decreasing in quantity.

To summarize, an access price $w\left(q_{2}\right)$ that is decreasing in $q_{2}$ exhibits two countervailing effects: On the one hand, if firm 2 obtains access to the new technology, the number of subscribers tends to go up relative to linear access prices. On the other hand, the likelihood that firm 2 will use the new technology decreases. It is possible that this trade-off, introduced by a quantity discount, can be alleviated through more-complex access price tariffs that condition $w$ not only on the quantity requested by the accessseeking firm, but also on other observables that depend positively on $u^{N}$ (such as profits, in analogy to the access tariff for the fixed fee in equation (12)).

14 We abstract from the issue that small competitors may be at a disadvantage as a result of quantity discounts at the wholesale level. Thus, we do not include the important long-run issue that the market may end up being more concentrated as a result of quantity discounts.

15 In the model in the Appendix, this requires that demand in the hinterlands depends on prices. 


\subsection{Alternative access tariffs}

We next further extend the set of considered (non-linear) access tariffs to discuss access-price policies (as the outcome of negotiations or regulatory intervention) that also play a role in the policy debate.

\section{Access options}

The investing firm 1 , prior to the investment, may want to sell an access option to firm 2. In our framework, this may take the following form: A fixed fee $F$ to be paid initially is non-optional. After the realization of $u^{N}$, firm 2 can choose the quantity $q_{2}$; the corresponding part of the access payment is optional.

The advantages and disadvantages of this type of negotiated contract or regulated access tariff can be immediately inferred by our preceding analysis. The fixed fee $F$ reduces the inefficiency arising from firm 2's socially inefficient adoption of the new technology after $u^{N}$ has been realized. However, we recall that fixed ex-ante fees have the disadvantage that they exclude firms that enter the market at a later time. In addition, barriers of entry may arise for small firms. Furthermore, a higher $w$ relaxes competition in the retail market, but tends to make technology adoption by firm 2 more likely. The lessening of competition may be welfare-increasing from a dynamic perspective, as it may make the investment profitable for certain levels of $I$.

Possibly, offering a menu of access contracts with one contract specifying the access option conditional on paying upfront $F$ allows for cost sharing at an ex-ante stage among firms already present in the market, while still leaving entry possible at a later stage, albeit at less-favorable terms at the margin.

\section{Capacity limits and demand requirements}

Another type of access contract specifies a capacity-i.e., a certain maximal number of firm 2 subscribers that this firm can access-for making a payment (in particular, a fixed fee $F$ ). If firm 2 could mix the new and old technologies (a fraction of subscriptions to the old and another to the new), this can be seen as a commitment by firm 2 to demand at least $\bar{q}$. A higher quantity may be available for additional access payments. This means that marginal costs are higher for large quantities than for small ones; the opposite situation prevails with quantity discounts.

In general, there are no clear-cut lessons concerning the implications of non-linear access prices since results depend on the level $\bar{q}$. If the capacity threshold is high relative to the realization of $u^{N}$, then we expect competition to be more intense, while the opposite holds true for low capacity relative to the realization of $u^{N}$ : Here, firm 2's high marginal costs for quantities $q_{2}>\bar{q}$ lead to high retail prices. Advantages and disadvantage of an additional fixed fee $F$ were discussed above. 
In practice, these kinds of contracts are also discussed with respect to (efficient) risk sharing between firms. The issues of risk sharing and, relatedly, the determination of the risk premium, depending on the types of contracting, and the chosen regulatory approach will be investigated in the following section.

\section{Risk averse firms and the risk premium}

\subsection{Preliminary considerations}

Under risk aversion, a firm considers the expected cash flow to be less valuable if it is more risky. ${ }^{16}$ Put differently, because of uncertainty, the value of expected profits has to be adjusted downward; here, we abstract from the time dimension, which is the topic of Section 5. Modern capital market theory suggests, however, that firms should ask for a risk premium for systematic, but not for idiosyncratic, risk since the former increases the costs of capital. If this were the only reason for a risk premium, we would immediately obtain the following result: Risk sharing of the investment and the corresponding determination of, say, a fixed access charge $F$ are irrelevant from an efficiency point of view. Put differently, the premium required, in total, to afford the investment is the same no matter how the risk is shared between the two firms.

This neutrality no longer holds if there are firm-specific reasons for risk aversion. The finance literature has identified a number of reasons why firms should be averse to idiosyncratic risk. ${ }^{17}$ In particular, frictions in the capital market play a key role in explaining firms' risk aversion. Broadly speaking, internal financing can be less "costly" than external financing. The efficient risk sharing between investing and access-seeking firms, then, depends on the firms' abilities to bear the risk of the investment and, in particular, on the firms' external financing needs and their access to the capital market. This may depend on the particular company; however, these parameters are endogenous. Regulation that conditions on these different abilities runs the risk of generating inefficiencies in the way that firms make their financing and other relevant firm decisions. In addition, financial intermediaries offer possible insurance mechanisms to firms. ${ }^{18}$

16 In our simple framework, we do not need to distinguish between cash flows and profits.

17 An overview and good access to this literature is provided by Ross et al. (2008).

18 In this section, we abstract from regulatory uncertainty. We could introduce regulatory uncertainty-in particular, after presenting our dynamic extension in the following section. The term "regulatory uncertainty" refers to the uncertainty that prevails after existing regulation is revised. Given the long time horizon to recover investments in NGA networks, this is an important issue. To the extent that regulatory uncertainty is part of the general uncertainty, one has to ask to what extent it contributes to systematic risk and, thus, justifies a higher risk premium. However, regulatory risk can also mean that future regulation is not a random event, but depends on market conditions. Using that definition, regulation responds in a predictable way to market outcomes and reduces expected profits of access- 


\section{Risk profile with fixed and variable access fees}

Comparing contracts with a fixed fee $F$ to contracts with a variable fee that depends on the quantity-i.e., the number of subscribers (e.g., $w q_{2}$ )—we obtain the following risk profiles for the two firms. Provided that-based on the ex-ante contracts offered-both firms offer the new technology, net profits with a fixed fee are

$$
\pi_{1}\left(u^{N}, u^{N}\right)-(I-F) \text { and } \pi_{2}\left(u^{N}, u^{N}\right)-F
$$

With a linear access tariff, net profits are

$$
\pi_{1}\left(u^{N}, u^{N} ; w\right)+w q_{2}\left(u^{N}, u^{N}\right)-I \text { and } \pi_{2}\left(u^{N}, u^{N} ; w\right)-w q_{2}\left(u^{N}, u^{N}\right) .
$$

Abstracting initially from the implications of $w$ for quantities $q_{1}$ und $q_{2}$, and postulating that contracts require that each firm bears the investment cost in accordance with its share of subscribers in the retail market, the comparison plays out as follows. Replacing the fixed fee $F$ with the access price $w$ rotates the profit function in terms of $u^{N}$. The investing firm obtains a relatively larger payment $w$ for a high realization of $u^{N}$ and a relatively lower contribution to its investment cost with a low realization of $u^{N}$. Thus, its profit function becomes steeper in $u^{N}$. By contrast, the risk profile of the accessseeking firm becomes flatter.

Result 4: A variable access payment that increases in the number of subscribers, instead of a fixed payment for access, shifts more risk to the investing firm.

Figure 1 illustrates this finding. 


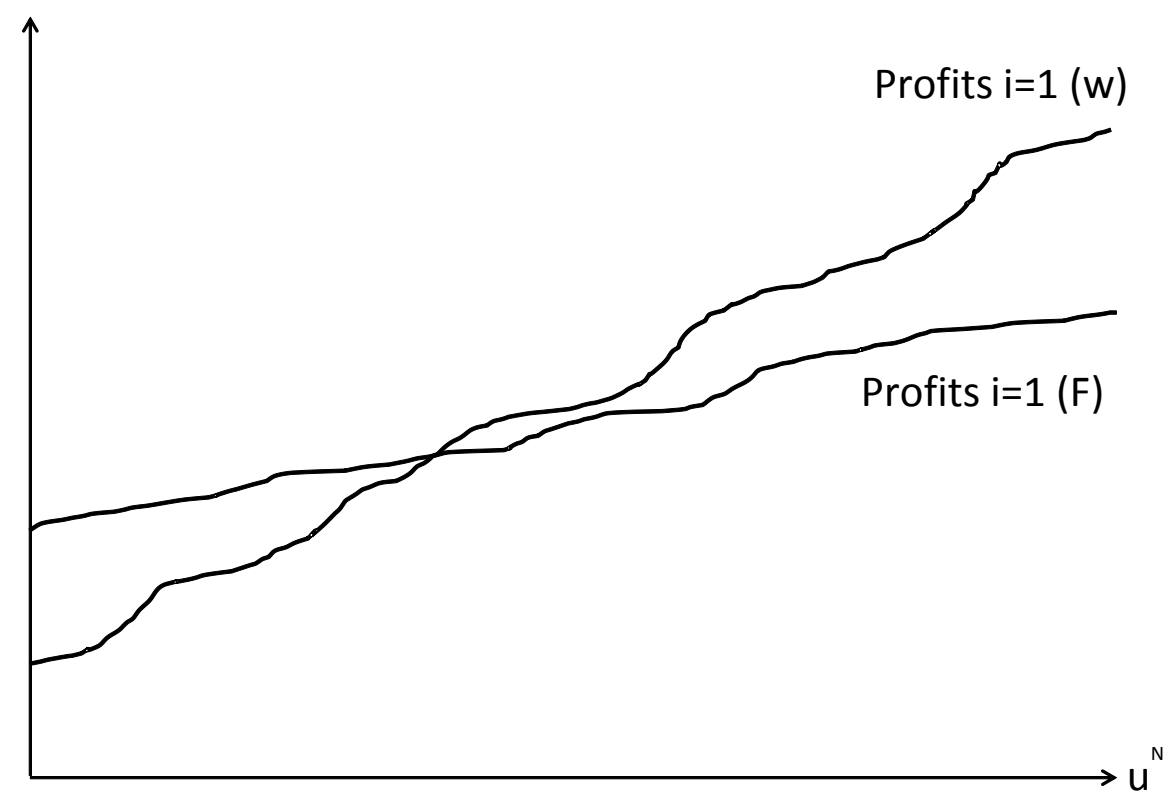

Figure 1: Risk profile of the investing firm

If the goal of regulation is to ensure a balanced allocation of risk to the two firms, our findings suggest (subject to the caveats on ex-ante access fees) that a fixed fee is desirable. Thus, as long as no late entry can be expected and no foreclosure of small firms feared, this provides additional support for a fixed ex-ante fee. (Note that we have set marginal costs-i.e., costs per subscriber-equal to zero. If they are positive, the fixed fee has to be accompanied by a price per subscriber equal to marginal cost.)

\section{Risk profile with optional fees}

We extend our discussion to the case of optional fixed fees. As a first step, suppose that firms do not compete in the retail market because, for example, they serve distinct consumer groups. In this case, the risk profiles of the two firms-i.e., the shape of the profit function-is as follows. Recall that only firm 1 uses the new technology for low realizations of $u^{N}<u^{*}$ if the payment of $F$ is optional. Thus, firm 1 obtains $F$ as a contribution to its investment costs only if $u^{N} \geq u^{*}$.

Figure 2 illustrates the corresponding risk profile, which features a discontinuity at $u^{N}=u^{*}$ for firm 1 . Note that this figure illustrates an environment in which firms do not compete. Therefore, profits $\pi_{2}\left(u^{N}, u^{O}\right)$ are constant in $u^{N}$, as the performance of the new technology is irrelevant for firm 2 if it has decided to continue using the old technology. The insight under no competition essentially carries over to market environments in which there is little competition, with only the modification that $\pi_{2}\left(u^{N}, u^{O}\right)$ is decreasing in $u^{N}$, albeit not reacting much to $u^{N}$. The shape of the profit function of firm 1 is similar; the jump at $u^{N}=u^{*}$ is a bit less pronounced. 


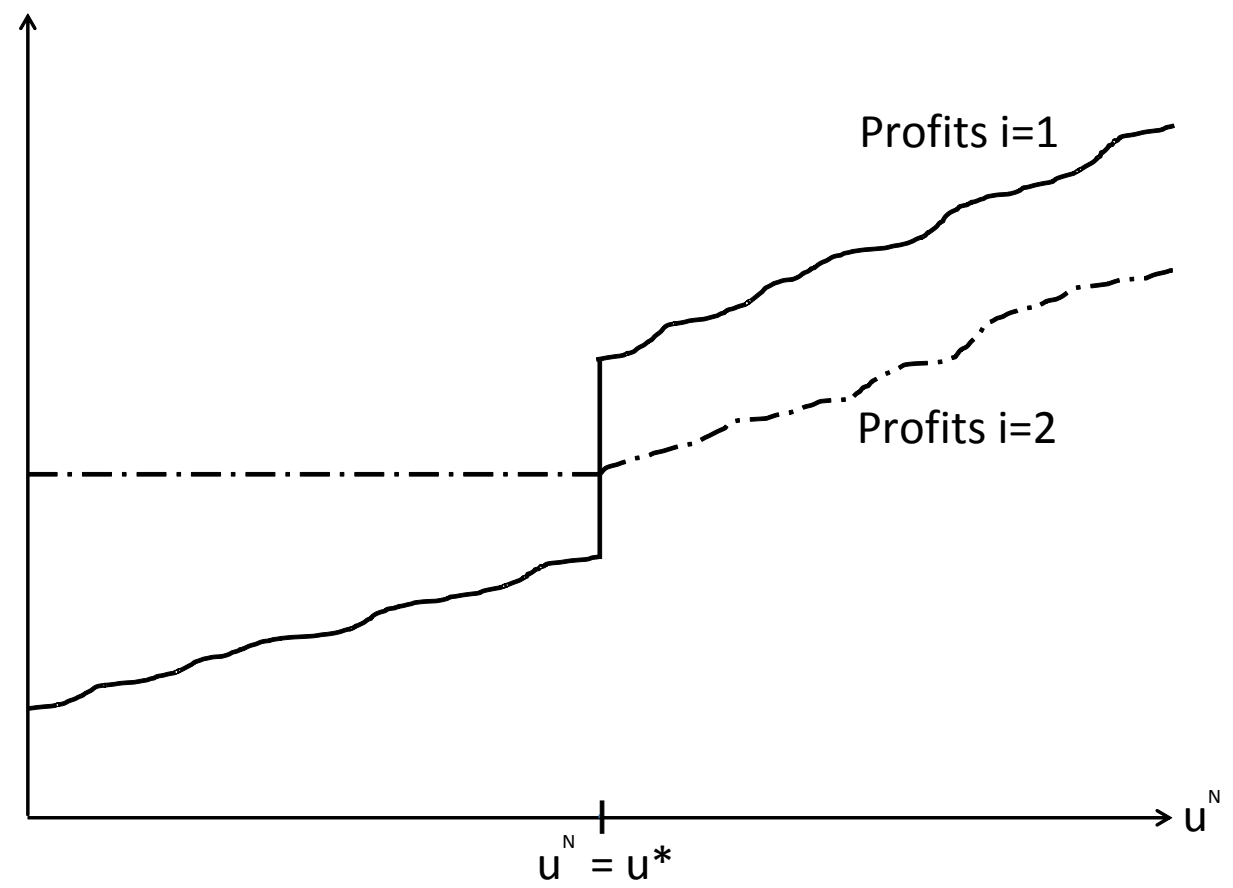

Figure 2: Risk profile under weak competition

If competition is intense, the picture may change dramatically, as depicted in Figure 3. In particular, firm 1's risk profile looks drastically different. Here, intense competition makes realizations slightly below $u^{N}=u^{*}$ rather attractive for firm 1 , as it makes high profits when facing a competitor with poor quality. This means that the jump at $u^{N}=u^{*}$ goes in the opposite direction. In the case of firm 2 , the risk profile has the feature that $\pi_{2}\left(u^{N}, u^{O}\right)$ is decreasing in $u^{N}$, reacting strongly to changes in $u^{N}$, as its disadvantage becomes more and more pronounced for higher $u^{N}$. 


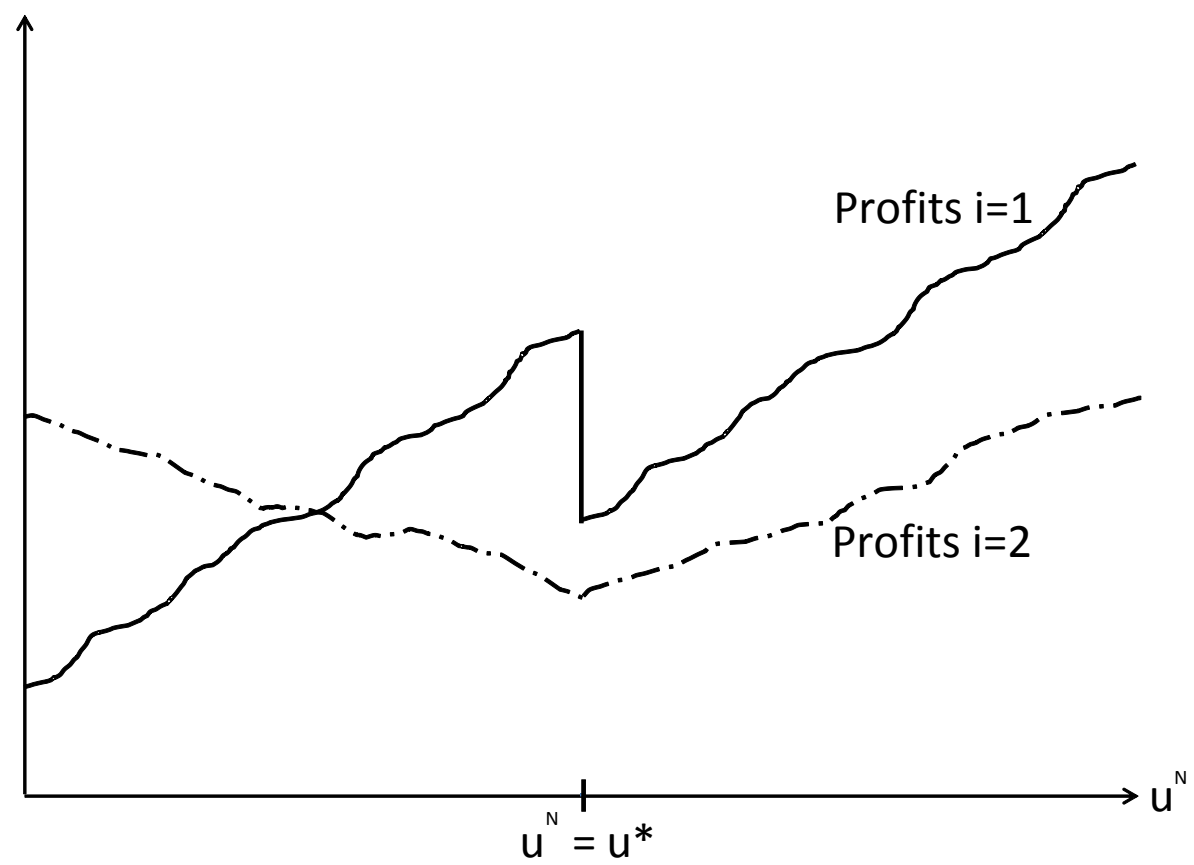

Figure 3: Risk profile under strong competition

Result 5: If the access contract consists of an optional fixed fee, the risk profile of the non-investing firm has the feature that its profits are decreasing in $u^{N}$ as long as it decides not to take the option-i.e., $u^{N}<u^{*}$. Under intense competition, the risk profile may be non-monotone, and average profits for the investing firm for low realizations of $u^{N}<u^{*}$ may, in principle, be at a level similar to the average profits for high realization $u^{N}>u^{*}$.

Based on the risk profiles, it is possible to calculate measures of risk, such as variance in numerical examples. It is even possible to calculate the extent to which the systematic risk is borne by the two firms ("cash-flow beta"), which can then be used to determine the investing firm's risk premium. A computational approach in this direction appears to be interesting but is beyond the scope of the paper.

\section{Discussion: Dynamic access fees}

In this section, we include the time dimension in our discussion. Initially, we still suppose that there is a single investment $I$ to be made. Firm 2 has to decide the point in time at which to start accessing the new technology.

\subsection{Access fees over time}

In this subsection, we postulate that there is a single investment period, which implies that the type of decision problem faced by firm 2 is the same as in the previous sec- 
tions. Profits following the investment occur over several periods $t=1,2, \ldots$. In every period, the market evolution for the new technology is captured by the realization $u^{N}(t)$. For simplicity, we suppose that profits in period $t$ depend on $u^{N}(t)$ and, if no access has taken place, $u^{O}$ which is independent of time. In particular, if both firms use the new technology in period $t$ given realization $u^{N}(t)$, equilibrium profits in the retail market are $\pi_{i}\left(u^{N}(t), u^{N}(t)\right)$. If only firm 1 uses the new technology, equilibrium profits in the retail market are $\pi_{i}\left(u^{N}(t), u^{O}\right)$.

\section{Sharing the investment risk and dynamic efficiency}

For several reasons, a firm may be averse to idiosyncratic risk, even though, according to the standard approach (CAPM), this should not be the case. There may be benefits from cash-flow smoothing, as outside financing is costly due to capital market frictions. Consequently, the distribution of access revenues over time also may become an important determinant of investment decisions.

First, we consider a deterministic fixed fee $F(t)$, which may vary over time. To use the new technology at time $t$, firm 2 has to pay $F(t)$. We postulate that the access decision is irreversible, in the sense that it is optimal to continue to use the new technology and pay $F\left(t^{\prime}\right)$ for all $t^{\prime}>t$ once it has been adopted by firm 2 .

Thus, firm 2 has to determine the optimal point in time at which, depending on the market development, it seeks access to the new technology. We stipulate that $u^{N}(t)$ is weakly monotone over time since the ongoing development of new services increases consumers' willingness to pay. If $F(t)$ is constant or decreasing over time, this implies that there is an optimal point in time $t^{*}$ after which it is profit-maximizing for firm 2 to make the payment for access. The larger $t^{*}$ is, the less efficient the outcome is.

The problem of delayed adoption becomes more severe under uncertainty. Uncertainty over future realizations of $u^{N}(t)$ makes waiting and using the old technology relatively more attractive. ${ }^{19}$ More uncertainty increases the value of waiting. Since, in our framework, $u^{N}(t) \geq u^{O}$ for all $t$, waiting is never socially efficient; however, it may occur in the market. This suggests that $F(t)$ should initially be low. To obtain the same cost contribution from the access-seeking firm, this may require that $F(t)$ must be larger in later periods. To the extent that an initially low $F(t)$ enables early adoption by firm 2 , this payment may be reduced in later periods, relative to an $F$ applied uniformly over all periods. Considering that $u^{N}(t)$ is increasing over time and the uncertainty of realization $u^{N}(t)$ is decreasing over time, back-loaded access fees may increase overall efficiency. Note, again, that for this argument, it is important that access is optional for

19 Determining the value for waiting due to uncertainty is an important contribution [of to?]the literature on real options; see, in particular, Dixit and Pindyck (1994). Guthrie $(2006,2012)$ discusses applying the real options approach to telecommunications. 
firm 2 . Also note that to preserve firm 1's incentives to invest, retail competition following access should not be too intense (or it should be dampened through higher marginal charges). Otherwise, there may be failure to invest in the first place. Finally, note that the adoption of a per-subscriber fee $w(t)$ can, again, lead to a more efficient adoption of the new technology by firm 2 , as argued in Section 3.

\subsection{Dynamic investment paths}

We extend the previous analysis by allowing the investing firm to choose an investment path over time, $I(t)$. We extend our formal framework as follows: Denoting the spending on investment at time $t$ by $I(t)$, the overall investment volume is $S_{I}(t)=I(1)+\ldots+I(t)$ (for simplicity, we abstract from discounting). The consumer utility in period $t$ now depends on the overall investment up until $t, S_{I}(t)$. A high realization of $u^{N}$ becomes more likely the higher $S_{I}(t)$ is. In addition, the probability distribution over $u^{N}$ may depend not only on the investment level at point, $t$ but also on the exact time path. We discuss the latter issue below.

\section{Efficient investment path}

We explore how a dynamic access tariff-in the form of fixed fees $F(t)$, for exampleaffects the investment path and its efficiency properties. On efficiency grounds, the optimal path $I(t)$ depends on various factors. Due to the irreversibility of the investment, there is, from an efficiency perspective, value to waiting, provided that the success of the new technology and, thus, the future path of $u^{N}(t)$ is uncertain. However, early investments also make it possible to learn about future success. ${ }^{20}$

We note that, with imperfect capital markets, the chosen investment path $I(t)$ may also depend on the financial resources available to the firm. In this case, high access payments (provided that the access-seeking firm makes use of the option to access the technology) may help the investing firm to finance the investment upfront and can be seen as a way to generate internal financing (in particular, if investments can be spread over time and space so that access payment in one region helps finance the investment in another region).

\section{Incentives for earlier investments}

The privately optimal investment path for firm 1 will typically differ from the socially efficient path. As is well known, the investing firm is typically not able to extract all rents in the market, even if it finds itself in a monopoly position. In addition, in the presence of

20 Physical restrictions should also affect the maximal possible or (due to cost considerations) acceptable speed of roll-out of the new technology. 
imperfect competition, there is another party that may obtain some of the rents generated by the investment.

To understand the forces at play, it is useful to first neglect the time dimension and allow the investing firm to decide on the scale of its investment. If the investment is not a simple yes/no decision but, rather, a decision of scale, variable access fees have an efficiency advantage over fixed fees (especially if paid ex ante). For simplicity, consider the extreme case in which firms do not compete in the retail market. With a fixed exante access fee, the investing firm internalizes its own profits in the retail sector, plus the fixed contribution by the access-seeking firm, as long as contracting is incomplete with respect to the scale of the investment. To be more precise, absent competition, the investing firm's profits are independent of the profits obtained by the access-seeking firm. By contrast, a variable access payment implies that the investing firm also benefits from a larger number of subscribers to the access-seeking firm as a result of its investment.

If the scale of the investment is built up over time along an investment path, this comparison between variable and fixed access fees continues to apply. Here, a variable access fee may lead to quicker investments, as investment incentives are stronger, the greater the speed of the investment. Similarly, incentives along the investment path to invest earlier are strengthened as access payments are more front-loaded, as this allows the investing firm to obtain a larger share of the surplus generated by the investment in early periods.

The preceding discussion, however, presumes that the access payment depends only indirectly-i.e., through the structure of the access price-on investment volume and the investment path. Alternatively, fixed or variable payments could depend directly on the investment path-e.g., by applying $F(t, I(t))$ or $w(t, I(t))$. Bringing investments forward is then compensated by a higher $F(t, I(t))$ or $w(t, I(t))$ in early periods. As a larger investment increases realizations of $u^{N}(t)$, the access-seeking firm may also seek early access.

\section{$6 \quad$ Concluding Remarks}

This paper provides a framework for exploring the allocative and welfare effects of various access tariffs in an environment in which the value of the new technology is uncertain and in which a firm has to make an investment decision and grant access to a competitor. Introducing uncertainty allows us to distinguish between two types of exante contracts: those that include non-optional access payments (co-investment) and those that allow the access-seeking firm to decide whether to use of the access option once the uncertainty has been resolved. We also consider ex-post contracts, which are signed after the investment has been made (and the uncertainty resolved). 
We proceed in three steps: First we consider a world with uncertainty, in which an investment decision and an access decision are made only once, and firms are riskneutral. Second, we introduce risk aversion among firms. Third, returning to risk-neutral firms, we explore when the access-seeking firm chooses to access the new technology and the investing firm makes its investment(s).

Our paper should be seen as explorative. We aim to highlight different forces at play without providing a full characterization of privately and socially optimal contracts. Also, by restricting ourselves to the use of reduced profit functions (albeit with a micro foundation, which is provided in the Appendix), we could not explicitly provide parameter ranges for certain results to hold. The advantage of our framework is that it allows us to uncover various forces at play in a simple setting. However, by analyzing a fully specified model, it should be possible to obtain additional welfare results.

Future work may want to develop tractable, micro-founded models that explicitly incorporate risk aversion arising from capital-market imperfections. It may also want to pay more attention to timing decisions by firms in a dynamic game. While we touch upon both issues in the two preceding sections, much work remains to be done in these directions. 


\section{$7 \quad$ Appendix}

Here, we illustrate the insights derived in the main text by focusing on a particular model. The analysis in the main text relied on a reduced form, which allowed us to focus on the main mechanisms at play. Here, we provide a specific model that meets all the reduced-form assumptions in the main text. We rely on the adaptation of the standard Hotelling-duopoly provided in Inderst und Peitz (2012a).

\section{Competition for consumers: The standard case}

We consider competition between two horizontally differentiated firms in the Hotelling model with hinterlands. Firms are located at the extreme points of the $[0,1]$-interval. Consumers are uniformly distributed on this interval. A consumer at location $x$ incurs disutility $\tau x$ if she subscribes to firm 1 and $\tau(1-x)$ if she subscribes to firm 2 . Thus, the utility gross of the price is $u_{1}-\tau x$ if she subscribes to product 1 and $u_{2}-\tau(1-x)$ if she subscribes to firm 2. The parameter $\tau$ is a measure of the degree of product differentiation and, thus, of the intensity of competition.

The interval is populated by a mass $M$ of consumers. In addition, each firm has a hinterland with consumer mass $m_{i}$ which it serves exclusively. The hinterland includes consumers with particularly strong preferences for one of the two firms that are beyond reach for the competing firm; each firm operates as a monopolist in its own hinterland. Each firm does not know the location of consumers and also cannot discriminate between a consumer from its hinterland and a consumer from the imperfectly competitive segment. First, we consider the situation in which the number of viewers in the monopoly segments is constant. In other words, the demand in the hinterland is perfectly priceinelastic. We assume that the hinterland is sufficiently small, with the property that neither of the two firms has an incentive to extract the full surplus from the hinterland or to compete in the imperfectly competitive segment.

Firm $i$ sets price $p_{i}$. Thus, a consumer $x$ within the competitive segment obtains net neutrality $u_{1}-\tau x-p_{1}$ if she subscribes to firm 1 and $u_{2}-\tau(1-x)-p_{2}$ if she subscribes to firm 2. Firm $i$ incurs constant marginal costs of production $k_{i}$.

\section{Old and new technology}

The starting point is the situation in which both firms can use the old technology with $u_{i}=u^{O}$. If firm 1 has invested in the new technology, $u_{1}=u^{N}$. If firm 2 obtains access to firm 1's new technology, $u_{2}=u^{N}$. 


\section{Competition in the standard model}

In the competitive segment, there is a consumer $\hat{x}$ who is indifferent between the two firms. It satisfies $u_{2}-\tau(1-\hat{x})-p_{2}=u_{1}-\tau \hat{x}-p_{1}$. Solving for $\hat{x}$, we obtain

$$
\hat{x}\left(p_{1}, p_{2}\right)=\frac{1}{2}+\frac{1}{2 \tau}\left[\left(u_{1}-p_{1}\right)-\left(u_{2}-p_{2}\right)\right]
$$

In this segment, demand for operators 1 is $\hat{x}$ and demand for product 2 is $1-\hat{x}$.

Thus, demands for firms 1 and 2 are

$$
q_{1}=m_{1}+M \hat{x} \text { and } q_{2}=m_{2}+M(1-\hat{x}) .
$$

Profits of firm 1 (gross of any fixed costs) are

$$
\pi_{1}=q_{1}\left(p_{1}-k_{1}\right)=\left(m_{1}+M \hat{x}\right)\left(p_{1}-k_{1}\right) \text {. }
$$

Similarly, profits of firm 2 are:

$$
\pi_{2}=q_{2}\left(p_{2}-k_{2}\right)=\left(m_{2}+M(1-\hat{x})\right)\left(p_{2}-k_{2}\right) .
$$

Let us define parameters $\hat{m}_{1}=m_{1} / M$ and $\hat{m}_{2}=m_{2} / M$. We can then rewrite profit functions as

$$
\pi_{1}=M\left(\hat{m}_{1}+\hat{x}\right)\left(p_{1}-k_{1}\right) \text { and } \pi_{2}=M\left(\hat{m}_{2}+(1-\hat{x})\right)\left(p_{2}-k_{2}\right) .
$$

Maximizing profits with respect to price and rewriting the first-order conditions yields best-response functions

$$
p_{1}=\tau \hat{m}_{1}+\frac{1}{2} k_{1}+\tau \frac{1}{2}+\frac{1}{2}\left[u_{1}-u_{2}\right]+\frac{1}{2} p_{2}
$$

and

$$
p_{2}=\tau \hat{m}_{2}+\frac{1}{2} k_{2}+\tau \frac{1}{2}+\frac{1}{2}\left[u_{2}-u_{1}\right]+\frac{1}{2} p_{1} .
$$

Nash equilibrium prices are:

$$
\begin{aligned}
& p_{1}^{*}=\frac{2}{3} k_{1}+\frac{1}{3} k_{2}+\tau \frac{4 \hat{m}_{1}}{3}+\tau \frac{2 \hat{m}_{2}}{3}+\tau+\frac{1}{3}\left(u_{1}-u_{2}\right), \\
& p_{2}^{*}=\frac{2}{3} k_{2}+\frac{1}{3} k_{1}+\tau \frac{4 \hat{m}_{2}}{3}+\tau \frac{2 \hat{m}_{1}}{3}+\tau+\frac{1}{3}\left(u_{2}-u_{1}\right) .
\end{aligned}
$$

The price difference in equilibrium is, therefore, 


$$
\left[p_{2}^{*}-p_{1}^{*}\right]=\frac{2}{3}\left[u_{2}-u_{1}\right]+\frac{1}{3}\left(k_{2}-k_{1}\right)+\tau \frac{2}{3}\left(\hat{m}_{2}-\hat{m}_{1}\right)
$$

The price difference increases in the vertical differentiation $u_{2}-u_{1}$, in the cost difference $k_{2}-k_{1}$, and in the difference in the size of each firm's hinterland $\hat{m}_{2}-\hat{m}_{1}$.

\section{Equilibrium profits}

In equilibrium, the indifferent consumer is located at

$$
\hat{x}^{*}=\frac{1}{2}-\frac{1}{6 \tau}\left(u_{2}-u_{1}\right)+\frac{1}{6 \tau}\left(k_{2}-k_{1}\right)+\frac{1}{3}\left(\hat{m}_{2}-\hat{m}_{1}\right) .
$$

Using this expression, together with the expressions for equilibrium price, we obtain equilibrium profits

$$
\begin{aligned}
& \pi_{1}^{*}=M \frac{1}{2 \tau}\left(\frac{1}{3}\left(u_{1}-u_{2}\right)+\frac{1}{3}\left(k_{2}-k_{1}\right)+\frac{2 \hat{m}_{2}}{3(1 / \tau)}+\frac{4 \hat{m}_{1}}{3(1 / \tau)}+\tau\right)^{2}, \\
& \pi_{2}^{*}=M \frac{1}{2 \tau}\left(\frac{1}{3}\left(u_{1}-u_{2}\right)+\frac{1}{3}\left(k_{1}-k_{2}\right)+\frac{2 \hat{m}_{1}}{3(1 / \tau)}+\frac{4 \hat{m}_{2}}{3(1 / \tau)}+\tau\right)^{2} .
\end{aligned}
$$

In particular, if firm 1 use the new technology, while firm uses the new one, equilibrium profits are

$$
\begin{aligned}
& \pi_{1}^{*}=\pi_{1}\left(u^{N}, u^{O}\right)=M \frac{1}{2 \tau}\left(\frac{1}{3}\left(u^{N}-u^{O}\right)+\frac{1}{3}\left(k_{2}-k_{1}\right)+\frac{2 \hat{m}_{2}}{3(1 / \tau)}+\frac{4 \hat{m}_{1}}{3(1 / \tau)}+\tau\right)^{2}, \\
& \pi_{2}^{*}=\pi_{1}\left(u^{N}, u^{O}\right)=M \frac{1}{2 \tau}\left(\frac{1}{3}\left(u^{N}-u^{O}\right)+\frac{1}{3}\left(k_{1}-k_{2}\right)+\frac{2 \hat{m}_{1}}{3(1 / \tau)}+\frac{4 \hat{m}_{2}}{3(1 / \tau)}+\tau\right)^{2} .
\end{aligned}
$$

\section{Extension: Price-dependent total demand}

The model from above has the property that the total number of active consumers is perfectly price-inelastic. Here, we sketch the extension with price-dependent hinterlands-i.e., we postulate that $m_{1}\left(p_{1}\right)$ is decreasing in $p_{1}$ and $m_{2}\left(p_{2}\right)$ decreasing in $p_{2}$.

To connect to the analysis in the main text, we introduce a linear access fee $w$ which gives rise to access revenues of firm 1 when investing and granting access. The profit function of firm 1 is

$$
\begin{aligned}
\pi_{1} & =\left(p_{1}-k_{N}\right)\left(M \hat{x}\left(p_{1}, p_{2}\right)+m_{1}\left(p_{1}\right)\right)+\left(w-k_{N}\right)\left(M\left(1-\hat{x}\left(p_{1}, p_{2}\right)\right)+m_{2}\left(p_{2}\right)\right) \\
& =\left(p_{1}-w\right)\left(M \hat{x}\left(p_{1}, p_{2}\right)+m_{1}\left(p_{1}\right)\right)+\left(w-k_{N}\right)\left(M+m_{1}\left(p_{1}\right)+m_{2}\left(p_{2}\right)\right) .
\end{aligned}
$$


Firm 2' profit function is

$$
\pi_{2}=\left(p_{2}-w\right)\left(M\left(1-\hat{x}\left(p_{1}, p_{2}\right)\right)+m_{2}\left(p_{2}\right)\right) .
$$

Equilibrium prices $p_{1}^{*}$ and $p_{2}^{*}$ depend on the access price $w$. In the case of perfectly price-inelastic hinterlands, we have $d p_{2}^{*} / d w=1$ und $d p_{1}^{*} / d w=1$ (see, in particular, de Bijl and Peitz, 2006). By contrast, with price-dependent hinterlands we have $d p_{2}^{*} / d w<1$ since a price increase leads to lower demand in the monopoly segment of a firm. The latter implies that a higher (linear) access price for the new technology leads to lower profits of firm 2 and $d p_{1}^{*} / d w<1$ (i.e., firm 2 passes an increase in access costs only partially on to consumers).

The present model features an important asymmetry between firms: Firm 1 as the integrated firm, does not have opportunity costs (depending on $w$ ) if it sells its service to consumers in its own hinterland, $m_{1}\left(p_{1}\right)$. By contrast, firm 2 has to pay the access price and, thus, incurs cost $w>k_{N}$ when selling to consumers in its hinterland, $m_{2}\left(p_{2}\right)$. Consequently, firm 1 tends to set a lower price than firm 2 in equilibrium (see de Bijl und Peitz, 2006). Therefore, there is partial foreclosure, and a higher access price $w$ tends to lead to more-asymmetric market outcomes. This may further increase the deadweight loss.

\section{Introducing uncertainty and risk}

Suppose, now, that $u^{N}$ is drawn from the interval $\left[u^{O}, \bar{u}\right]$ according to the cumulative distribution function $G\left(u^{N}\right)$. For instance, with a fixed and non-optional access fee and $w=k_{N}$, firm i's expected profit (gross of investment cost and any fixed payments) is

$$
\int_{u^{A}}^{\bar{u}} \pi_{i}\left(u^{N}, u^{N}\right) d G\left(u^{N}\right)
$$

We note that, in the case of perfectly price-inelastic hinterlands, $\pi_{i}\left(u^{N}, u^{N}\right)$ is independent of $u^{N}$. This implies that, consumers fully retain the higher consumer benefit due to a better technology. Hence, if a variable access markup is not allowed, a firm never has an incentive to invest in a technology that its competitor can use, as total industry profits are constant in $u^{N}$. Industry profits are no longer constant when demand in the hinterlands is price-dependent, and a firm invests if investment costs are sufficiently low. 21

With $G\left(u^{N}\right)$ and equilibrium profit and demand as functions of $\left(u_{1}, u_{2}\right)$ as derived above, we have provided a specific model for the expressions used in the main text.

21 Another possibility to obtain non-constant industry profits is to assume that a better technology increases horizontal differentiation between firms, i.e. $\tau$ is increasing in $u$. 
They can also be used for numerical illustration when assigning value to the parameters of the model. 


\section{References}

Armstrong, M. and D. Sappington (2007), Recent Developments in the Theory of Regulation, in M. Armstrong und R. Porter (eds.), Handbook of Industrial Organization, Band III, North-Holland.

Bourreau, M., Cambini, C. and P. Dogan (2012), Access Pricing, Competition, and Incentives to Migrate from "Old" to "New"Technology, International Journal of Industrial Organization 30, 713723.

Bourreau, M., Cambini, C. and S. Hoernig (2013), My Fibre or Your Fibre? Cooperative Investment, Uncertainty and Access, mimeo.

Brito, D., Pereira, P., and J. Vareda (2012), Incentives to Invest and to Give Access to New Technologies, Information Economics and Policy, forthcoming.

Cambini, C. and Jiang, Y. (2009). "Broadband Investment and Regulation. A Literature Review." Telecommunications Policy, 33, 559-574.

de Bijl, P. and M. Peitz (2006), Local Loop Unbundling: One-Way Access and Imperfect Competition, in R. Dewenter and J. Haucap (eds.), Access Pricing: Theory and Practice, Elsevier Science, 91-117.

Dixit, A. K. and R. S. Pindyck (1994), Investment under Uncertainty. Princeton University Press.

Economides, N. (2002), Real Options and the Costs of the Local Telecommunications Network, in J. Alleman und E. Noam (eds.), The New Investment Theory of Real Options and its Implications for Cost Models in Telecommunications, Kluwer.

Guthrie, G. (2006), Regulating Infrastructure: The Impact on Risk and Investment, Journal of Economic Literature 44, 925-972.

Guthrie, G. (2012), Regulated Prices and Real Options, Telecommunications Policy 36, 650-663.

Hori, K. and K. Mizuno (2006), Access Pricing and Investment with Stochastically Growing Demand, International Journal of Industrial Organization 24, 795-808.

Inderst, R. and M. Peitz (2012a), Network Investment, Access and Competition, Telecommunications Policy 36, 407-418.

Inderst, R. and M. Peitz (2012b), Market Asymmetries and Investments in NGA, Review of Network Economics 11(1), article 2.

Inderst, R., J. Kühling, K.-H. Neumann and M. Peitz (2012), Investitionen, Wettbewerb und Netzzugang bei NGA, Nomos-Verlag.

Nitsche, R., and L. Wiethaus (2011), Access Regulation and Investment in Next Generation Networks. A Ranking of Regulatory Regimes, International Journal of Industrial Organization 29, 263-272.

Pindyck, R.S. (2007), Mandatory Unbundling and Irreversible Investment in Telecom Networks, Review of Network Economics 6 (3), 274-298.

Ross, S. A., R. W. Westerfield and J. Jaffe (2007), Corporate Finance. McGraw Hill.

Vareda, J., and S. Hoernig (2010), Racing for Investment under Mandatory Access, The BE Journal of Economic Analysis \& Policy, 10(1). 